\title{
Practical aspects of project-based learning in the study of the discipline "Developing information systems"
}

\author{
Rimma D. Gutgarts \\ E-mail: gutgarc@gmail.com \\ Irkutsk National Research Technical University \\ Address: 83, Lermontov Street, Irkutsk 664074, Russia
}

\begin{abstract}
Analysis of modern publications dealing with project-based learning at the university has shown that they can be divided into two parts. The first part is devoted to theoretical and methodological issues and its authors are mainly pedagogical specialists. The second part is concrete examples of the application of the indicated teaching technology in various subject areas, including technical specialties. The literature also presents applications on the organizational and technological aspects of introducing project-based learning in the educational process at the university. The authors of the second part are teachers of specialized disciplines in the corresponding field of study (medicine, technology, creativity, economics, etc.). This article provides an example of the use of elements of project-based education as early as in Soviet higher education when teaching students with a specialization in "Information Technology" and their projection on a modern educational platform. The purpose of the study is to consider individual methodological issues and practical recommendations for applying the project method for students of study profiles related to the study of disciplines focused on information systems (IS) design. The result of the study is to focus on the possibility of introducing project-based training within an interdisciplinary nature, in particular, the participation of students studying in economic specialties in projects for the creation of functional IS. Advice is given on the distribution of the roles of students and their functions in a team working on a project.
\end{abstract}

Key words: information systems; project approach to training; competencies; information systems design; examples of project training; participants in project training.

Citation: Gutgarts R.D. (2020) Practical aspects of project-based learning in the study of the discipline "Developing information systems". Business Informatics, vol. 14, no 1, pp. 51-61.

DOI: $10.17323 / 2587-814 X .2020 .1 .51 .61$ 


\section{Introduction}

$\mathrm{O}$ ver the past few years, two terms have come to be actively used in the terminology of the learning process at all levels: "project-based learning" and "competencies." However, project-based training is still perceived as one of the non-traditional pedagogical technologies, although it is promoted for widespread use, especially in the process of higher education [1]. There are a fairly large number of publications on the subject of project-based training. For example, in the Scientific Electronic Library (https:// elibrary.ru) as of 5 January 2020, there were 180,649 of them.

A brief analysis of information sources on the indicated topics as applied to studying at a university has shown that they reflect the following features:

1. The main characteristics and features of project-based training are summarized, for example, in [2-4]

2. The introduction of design technology in the educational process is shown from the point of view of the priority direction of pedagogical activity [5]

3. Project activity is presented as the most popular and effective method of organizing work with students [3]. Moreover, this type of activity is not fundamentally new and in [3] there is a reference to the fact that the idea of project training arose in the United States in the 19 th century

4. The introduction of project training for students is influenced by such external factors as the development of science, technology, economics, and the organization of production [4]

5. The design method is considered as the optimal means of enhancing the motivation to learn among modern youth [6]

6. Training based on the implementation of projects is treated as one of the innovative teaching methods [7-9]

7. Project training is presented as one of the interactive pedagogical technologies aimed at implementing a personality-oriented approach to teaching methods [10]

8. Examples of the application of the design training method are given (for example, in the framework of the bachelor's degree in "Operation of transport-technological machines and complexes" [10], in the bachelor's programs in robotics profile [11], in the discipline "Computer technologies in documentation management "For the specialty" Management (by industry) "[1], in courses on power systems of the Faculty of Electromechanics at the University of Colima in Mexico [12]), as well as the experience and methodological basis for the use of project training (for example, at the Siberian Industrial University [13], in foreign practice [14]). Currently, there is not enough experience in the application of project-based instruction at Russian universities. Nevertheless, in particular, the Urals Federal University already has a certain basis in this matter and shares its methodological and practical achievements through online training

9. Project-based learning is understood as a model that is being introduced into the educational process instead of traditional teaching technology and it is fundamentally changing the process of getting an education [15]

10. Project-based learning embodies the idea of developmental learning [16].

\section{An example of the use of elements of project-based learning in a technical university}

Of the listed features, it is essential to mention the innovative component of project- 
based learning. The term "innovation" at the present stage of economic development in relation to management practice has been used actively relatively recently. However, elements of project-based learning have been used for a long time. One example is the experience of the Irkutsk Polytechnic Institute (now the Irkutsk National Research Technical University), where at the Department of Electronics and Computer Engineering (from the beginning of the 1970s to the beginning of the 1990s) there was a branch research laboratory of automated enterprise management systems (ONIL ASUP), which was engaged in the design, development and implementation of ACS (in the classic sub-systems structure) at seven enterprises in the electrical industry. Moreover, all design decisions were essentially standard and only finalized taking into account the specifics of each enterprise. In modern terminology for the implemented functionality, such an automated control system partially corresponded to the set of tasks of the following types of systems: CAD / $\mathrm{CAM}+\mathrm{MRPII}+\mathrm{CRM}+\mathrm{MES}+\mathrm{HRM}+$ EAM + BI. Almost all students who studied in the specialties "Automated control systems" and "Mechanized processing of economic information" took part in design decisions for all subsystems. The participation of students began from the 3 rd year and continued until the writing and defense of the graduation project. After graduation, some graduates were hired by the laboratory. Employees of ONIL ASUP periodically conducted classes with students. Such classes could be: lectures and practice in academic disciplines or its sections, practical classes, laboratory work. Collaboration was mutually beneficial. On the one hand, students were involved in the implementation of realistically implemented projects, learned to work in a team and even communicate with customers during the internship that took place at the same enterprises for which automated control systems were created. On the other hand, for ONIL ASUP there was an opportunity to attract additional workers and reduce the duration of projects. In addition, almost all teachers of the department also participated in projects. Over the 20-year history, on the basis of the topics of ONIL ASUP, its employees defended 19 candidate dissertations, and subsequently this scientific and practical base became the basis for five doctoral dissertations.

Unfortunately, at the moment, such a practice rarely takes place. Now the presence in universities of specialized units (centers, laboratories), whose activities are focused only on the implementation of business contracts and (or) grants, does not have widespread distribution.

One of the features of the design and development of IS currently consists in the isolation of this type of project activity in an independent direction. Typically they create typed design solutions and adapt them to the conditions of a particular enterprise by adjusting a set of parameters and (or) additional programming (example - 1C:Enterprise). Now standard design solutions for the automation of management activities at the corporate level are offered in the market of functional software (software) in a modular interpretation and can be acquired by any interested user.

Nevertheless, the use of the principles of project training has been preserved at the department until now. Throughout the existence of the department (over 50 years), completely different diploma projects have always been carried out. In fact, most students, starting from the second (or third) year, choose the topic of their future final qualification work (WRC) and, thus, all laboratory works in special disciplines is performed on a specific topic. I will give several topics of WRC in recent years:

- "The system of automated accounting of documents of the archive fund of the Russian Federation in organizations that are the sources of acquisition"

^ "Automated system for student media center IRNITU"

$\downarrow$ "Information system for the school of modern choreography "Steps"

$\checkmark$ "Automated accounting system for the rat- 
ing of cultural and creative activities of students"

"Automated order management system in the dispatching service of the enterprise BETON-STROY”

"Automated workplace of a customer service manager for "1-Megamir"

"Online service for applying for admission to IRNITU".

\section{Aspects of interaction of students of different profiles during project-based learning}

In universities that train specialists in creating information systems and, for example, economists, projects can be joint. The interaction between students of different areas of study contributes to the development of interdisciplinary communication and represents a transdisciplinary approach [4].

Such cooperation will be useful on both sides. On the one hand, developers of economic information systems will gain invaluable experience in communicating with real customers and understanding their functional needs. On the other hand, students of economic specialties who will inevitably use appropriate information systems in their professional activities will be able to learn how to formulate correctly their functional requirements. These can be requirements both for fundamentally new systems, and for already functioning systems in order to develop their functionality (if the project has such an orientation). "Now the creation of an information system is a task not only for programmers with the rare participation of management, but also for economic services included in the development of system modules" [17].

The stage of formation of functional requirements in the design of IS is the initial and extremely important stage. The time of implementation and the cost of the project will depend on the quality of its results. In addition, students of an economic profile will take part in testing the designed IS and critically evaluate the proposed solutions in a practical, professional aspect. This, in turn, allows, firstly, to see the mistakes made at the initial stage of working with requirements. Secondly, to be able to test the implemented requirements in the conditions of the created software product, as well as adjust the requirements as necessary. Thirdly, students of economic specialties can see instructions for users and recommend how to edit them, so that in case of problems when working with the system, some of them can be quickly and independently eliminated. Properly written instructions for the user are an indispensable assistant when working with the information system.

Students of economic specialties can also participate in a joint presentation of the project and present it to the appropriate audience. Thus, the skills of a public thematic report and knowledge of relevant terminology from the field of information technology (IT) will be acquired.

The participation of students of economic specialties in IS projects will reduce the gap between fundamentally different subject areas: IT and economics. It is the different terminology in real projects, especially at the initial stage, that often leads to some problems. According to statistics, about $2 / 3$ of the projects are not completed properly; for example, they stop ahead of schedule due to the fact that their continuation is inappropriate, or they end with a result that the customer does not need.

As projects in the development of the discipline "Designing information systems" can be selected, in particular, the following:

1. Information systems that solve a small 
number of functional tasks that are initiated by third-party clients (for example, systems for accounting, management, analysis, calculations). For such systems, there is no unified design solution in the functional software market. Systems on the market do not take into account the competitive advantages of a particular organization. Initiatively created systems can be designed, for example, to create data warehouses on the economic aspects of the enterprise (organization, company, large structural unit).

2. Information systems for specialized scientific organizations (including scientific departments of universities), if such systems do not include algorithms related to knowhow. This may be systems designed to perform specialized calculations and analysis of the results.

3. Computer programs based on the use of correct algorithms, but implemented on obsolete instrumental base (for example, DBMS, programming language, information storage and presentation technology, interface).

In [18], projects are classified by their nature at the macro level. According to such recommendations, IS projects can be considered as:

$\downarrow$ search (search and analysis of the suitability of similar ready-made design solutions)

$\downarrow$ creative (any design of IS necessarily contains elements of creativity, since in addition to formal algorithms it includes, for example, designing an interface)

$\checkmark$ applied (IS is always created in relation to a specific subject area)

$\checkmark$ role-based (team members in the project must have different specializations and interact with each other, because in the end they should get one software product).

\section{Features of the study of the discipline \\ "Designing information systems" in the context of project-based learning}

When studying the discipline "Designing information systems," students should gain theoretical knowledge on the design process as such, on methodological aspects and on the use of special tools, as well as acquire skills in creating design solutions at all stages of design, taking into account the compilation of the related design documentation. In this case, two fundamental approaches to the study of discipline are possible.

The first approach includes the following:

$\diamond$ to study the theoretical foundations of IS design, stages (steps) of the canonical design process and their content, tools used in the design

to acquire skills in applying the acquired knowledge in practice, i.e. prepare individual information systems design solutions and develop a computer program for them.

The second approach has the following features:

$\rightarrow$ tools used for designing IS, as well as theoretical issues are studied in the framework of special disciplines (for example, "CASE tools," "Web programming," "Information technology," "Object-oriented programming," "Networks and telecommunications," "Technologies for the development of software systems," "Organization of computers and networks," "Data management," "Theoretical foundations of automated control," etc.)

$\diamond$ in practice, perform the design of the IS (on an individual task) using previously studied and mastered tools, including the basic work for each stage, as well as programmatically implement individual design solutions, accompanying the finished program with instructions for its use (for the system pro- 
grammer or administrator) and instruction for the end user.

If you adhere to the first approach, then students studying the discipline "Designing information systems" acquire a combination of different knowledge, abilities and skills in all the main aspects of project activities in relation to the creation of IS. A student receives some "starting capital." However, the depth of development of the material will be clearly insufficient to be ready for independent design work.

Yet, training on the basis of the first approach may be quite appropriate if this discipline is one of the curriculum disciplines in professional areas that are not related to the IT sphere. For example, training in economic specialties does not require deep immersion in the subject of IS design. However, students should have an idea of what needs to be considered when creating IS for economic purposes.

In our opinion, it is advisable to consider the study of the discipline "Designing information Systems" in the framework of the second approach, i.e. pay attention to the study of tools and other specialized issues within the framework of special disciplines which will allow students to gain more in-depth knowledge in the relevant subject areas.

Thus, the study of the discipline "Designing information systems" will be based on the knowledge already acquired by students, as well as their skills and abilities. Then interest will be focused on the design process as such, i.e. on the content of all stages of design, taking into account certain aspects of the compilation of project documentation accompanying each of them.

The result of the education will be a real project of any IS. Moreover, the learning process itself is based on the use of practice-oriented technologies. In such conditions, the students will be able to fully demonstrate their creative abilities and skills in practice, as well as apply the knowledge gained in mastering related disciplines. The role of the teacher is to perform two main functions: 1) to act as the customer of the project and critically analyze its intermediate results and 2) to act as a consultant analyst and edit the project implementation vector in a timely way.

\section{Description of the main participants in the implementation of project-based learning to study the discipline "Designing information systems"}

Let's consider the distribution of roles, functions and responsibilities of project participants using the example of creating an IS of organizational and managerial type. Such projects are always designed to meet the challenges in a particular subject area. It is desirable to form a team of students to carry out such a project in accordance with the specifics of the supporting and functional subsystems.

\subsection{The subsystem of organizational support}

Mentor and tutor: teacher. $\mathrm{He}$ or she substantiates and formalizes the theme of a project which is interesting for students and corresponds to the direction of preparation. Topics can be based on the results of practical training, offered by graduates of a profile direction, already working in their specialty, initiated by municipal services, specific organizations, and other departments of the university. They substantiate the design methodology: canonical or RAD. They concretize the functionality of the project and give recommendations on team building on the basis of general professional training of students to the initial moment of project implementation. The teacher oversees the project and provides advice if necessary. 
An expert, who also can be a customer of the project. An expert may be:

$\downarrow$ a representative of the organization in which the student underwent practical training

$\downarrow$ a graduate working in the specialty profile

$\downarrow$ representative of the municipal service

$\checkmark$ representative of a specific organization or department of the university initiating the project.

The process of studying at the university is very dynamic and attracting experts, tutors and other specialists "from the outside" is very problematic, since these people are employed in the real sector of the economy and can not always attend classes at the scheduled time. Therefore, it is more reasonable to choose for these roles either teachers who are profiled at the faculty or related.

Project manager. Draws up a calendar plan of work for the project, organizes and provides private and general meetings between all project participants, distributes work, keeps track of completed work, monitors compliance with the work plan, records and resolves problems that arise, analyzes the work performed, and regulates the work plan. For the implementation of management processes uses special software for project management.

\subsection{The subsystem of information support}

Students: will specialize in designing a database, reference information, interfaces, forms of input and output documents.

\subsection{Software development subsystem}

Students: will be engaged in the justification and selection of software for the program implementation of design solutions, their programming, as well as debugging and testing of finished programs.

\subsection{The subsystem of mathematical support}

Students: will justify, if necessary, the choice of mathematical and (or) economic and mathematical methods that ensure the implementation of specialized algorithms.

\subsection{The subsystem of technical support}

Students: will be engaged in designing a set of technical means necessary and sufficient for the implementation of the project at the automation object.

\subsection{Functional modules}

Students: will perform analytical work (identification and formalization of functional requirements for the project, preparation of project documentation, preparation of tasks for programmers, preparation of presentations at the end of the project); must use CASE tools in their work for the preparation of project documentation.

In addition, the project team may include:

$\downarrow$ students playing the role of testers (a comprehensive check of the functional operability of the finished software product and the preparation of recommendations for writing instructions for end users and the system programmer or administrator); if necessary, can participate in the compilation of full instructions

$\downarrow$ students acting as technical writers (drawing up instructions for using the developed software and its technological support during the operation of the system at the automation object).

It is advisable that in the process of project implementation the roles among students are periodically redistributed. Thus, students will be able to at least partially master all types of work within each role. Then they will have an 
idea of the specifics of the content of the project as a whole.

\section{The relationship \\ of project training \\ and a competency-based approach}

In [7] it is emphasized that at present such requirements are imposed on employees as the ability to carry out project activities, and this is one of the required competencies. If we talk about university students, then this ability will be formed automatically if the process of studying disciplines in the curriculum is initially based on the technology of project training.

When comparing the qualification and competency-based approaches to education in [19], attention is focused on the fact that the latter is characterized by such features as a creative look at problem solving, the possibility of constructing an individual learning path and interactivity.

The competency-based approach is often opposed to the paradigm of education based on knowledge [19]. The author shows the unreasonableness of this view, since "...the assimilation of knowledge and the formation of competencies are not only mutually complementary, but also closely intertwined" [19].

In [20], it is noted that there are about 400 definitions of competencies. However, it is enough to approach this issue from a formal point of view and turn to dictionaries. Having studied the semantic meaning of the term "competencies" given in [21-24], we can conclude that the term "competency" is a synthesis of a single-valued sequence of the following phases:

1) obtaining a certain set of primary knowledge in a specific subject area

2) the acquisition of initial skills in the use of acquired knowledge to solve problems in the same subject area
3) the application in practice of acquired skills contributing to the acquisition of some skills that improve as time increases in the use of acquired knowledge and the acquisition of experience.

The process of practical application of knowledge, skills and experience in real conditions is associated with the generation of new knowledge that affects the need to adjust existing skills. As a result, a new experience appears. Thus, while a person works in a specialized subject area and positions himself in it as a specialist (or even an expert), his competence develops in a spiral.

Therefore, the presence of a student of a certain professional competence actually consists in acquiring a combination of knowledge, skills and abilities. The level of experience (as the sum of knowledge, skills and abilities) initially cannot be very high due to restrictions of age.

In addition to competencies based on knowledge, students should acquire knowledge, skills and abilities in the field of optimal distribution of time when doing personal work, as well as interacting with other students. This will allow them in the future to quickly adapt to the workforce and solve professional challenges in a timely way $[25,26]$.

\section{Conclusion}

The technology of training at the university, based on the application of the project method, allows us, in particular, to solve the following problems:

1. The ability to respond to rapid changes (the formulation of requirements for the project is iterative in nature and therefore they can be edited throughout the project; to comply with the project deadlines, you need to respond quickly to the adjustment of requirements) 
2. Redistribute, if necessary, roles among project participants

3. To interact among themselves to all project participants (the design and development of one information system inevitably requires this)

4. To show creative abilities (in any project, its intellectual component is an integral part).

In addition, the implementation of one project will certainly contribute to the development of communicative relations between all participants due to the need for continuous cooperation on a variety of issues.

The introduction of project training in the educational process of higher education cannot and should not be understood as another campaign. This process is characterized by complex informational, organizational, and technological components (the relationship between academic disciplines in the same department and the relationship between disciplines in related departments), which will require some editing of curricula and the content of individual disciplines. Changes of this kind, in turn, are very dependent on standards (regulations) from the Ministry of Science and Higher Education. In these standards, for a number of disciplines that are mandatory, the volume of hours for their development is very strictly set. Therefore, universities have significant limitations in the preparation of their curricula.

Thus, the implementation of project-based training in practice will require, firstly, editing the standards by the ministry, secondly, delegating more independence to universities in the preparation of curricula, and thirdly, accounting and exchange of experience already gained on a regular basis.

\section{References}

1. Shapovalova M.S. (2014) Peculiarities of using project-based training in information disciplines within the framework of the Federal State Educational Standards of higher education. Science and Education.

Bauman Moscow State University. Electronic journal, no 10, pp. 413-423. Available at: http://engineering-science. $\mathrm{ru} / \mathrm{doc} / 728379 . \mathrm{html}$ (accessed 19 December 2019) (in Russian).

2. Galchenko A.S., Gabova M.P., Sofyina V.N., Rastorgueva P.A. (2018) Project training of students and managers as a tool for effective training in project management. Modern Education: Content, Technologies, Quality, no 2, pp. 161-163 (in Russian).

3. Gladkova M.N., Vaganova O.I., Smirnova Zh.V. (2018) The technology of project-based learning in professional education. Problems of Modern Pedagogical Education, no 58-3, pp. 80-83 (in Russian).

4. Guzanov B.N., Baranova A.A., Lovcevich T.L. (2019) Project-based training at trans-professional education in a technical university. Professional Education and Labor Market, no 3-38, pp. 44-52 (in Russian). DOI 10.24411/2307-4264-2019-10305.

5. Vyskareva T.A. (2011) Project method of teaching in the system of higher education. Contemporary Higher Education: Innovative Aspects, no 1, pp. 5-12 (in Russian).

6. Kenebaeva D.B., Abdibekova L.M., Bekenova D.B. (2019) Application of the project method of training in the framework of the discipline "Multimedia technologies" for students of higher education institutions. Proceedings of the X International Scientific and Practical Conference "Innovative Technologies in Science and Education”, Penza, Russia, 20 January 2019, pp. 47-49 (in Russian).

7. Kudinova O.S., Skulmovskaya L.G. (2018) Project activity at the university as a basis for innovation. Modern Problems of Science and Education, no 4. Available at: http://science-education.ru/ru/article/ view?id=27928 (accessed 11 December 2019) (in Russian). 
8. Kovrov V.V. (2019) Project activity as an innovative resource in ensuring the quality of professional training of students at the university. Problems of Modern Pedagogical Education, no 62-2, pp. 119-121 (in Russian).

9. Nurmaganbetova M.S. (2017) Project education as one of the innovative methods of training. Proceedings of the VII Russian Scientific and Practical Conference "Youth and the State: Scientific and Methodological, Socio-Pedagogical and Psychological Aspects of the Development of Modern Education. International and Russian Experience”, Tver, Russia, 23-30 October 2017, pp. 80-85 (in Russian).

10.Komarova L.V. (2014) Achievement of quality of training as a result of development of project technologies in profile education. Contemporary Higher Education: Innovative Aspects, no 4, pp. 91-95 (in Russian).

11.Shakhtarin B.I., Veltischev V.V. (2016) Project training in bachelor programs in the field of robotics. Civil Aviation High Technologies, vol. 19, no 05, pp. 54-60 (in Russian).

12.Betancourt R.J., González-López J.M., Espejo E.B., Pérez-González M.A., Laureano E.V., Ledesma J.A. (2018) Virtual instrumentation based learning methodology for teaching power system measurement and protection. Computer Applications in Engineering Education, vol. 27, no 6, pp. 1555-1570. DOI: 10.1002/cae.22170.

13.Protopopov E.V., Feoktistov A.V., Temlyantsev M.V., Gordeeva O.V., Vasilieva M.B. (2017) Project training as a tool for integrating an university's activities into the regional educational space (experience in implementing project training technology at SIBGIU). Bulletin of the Siberian State Industrial University, no 4 (22), pp. 63-69 (in Russian).

14.Souza M., Moreira R., Figueiredo E. (2019) Students perception on the use of project-based learning in software engineering education. Proceedings of the XXXIII Brazilian Symposium on Software Engineering (SBES 2019), Salvador, Bahia, Brazil. 23-27 September 2019, pp. 537-546. DOI: 10.1145/3350768.3352457.

15.Sycheva S.M., Arzumanova R.A. (2019) Project training as a key to preparing a successful specialist. Vestnik Universiteta, no 6, pp. 32-37 (in Russian). DOI 10.26425/1816-4277-2019-6-32-37.

16. Filippov V.M. (2019) Preparation of a dissertation should be difficult, and the defense should be simple and easy. Higher Education Today, no 9, pp. 2-7 (in Russian). DOI: 10.25586/RNU.HET.19.09.P.02.

17.Vinogradova E.Yu. (2018) Current issues of designing and implementing corporate systems for supporting management decision-making at the enterprise. Bulletin of the Far Eastern Federal University. Economics and Management, no 1, pp. 102-111 (in Russian). DOI: https://dx.doi.org/10.24866/2311-2271/2018-1/102-111.

18.Fateeva I.A., Kanatnikova T.N. (2013) Project method as a priority innovative technology in education. Young Scientist, no 1, pp. 376-378 (in Russian).

19.Golovyatenko T.A. (2019) Professional competence of a university teacher as a problem. Higher Education Today, no 10, pp. 15-19 (in Russian). DOI: 10.25586/RNU.HET.19.10.P.15.

20.Korchemny P.A. (2017) The problem of the competence approach from the position of the activity approach as a methodological basis in Russian education. Proceedings of the VIII International Symposium "International Research in Psychology of Security and Their Modern State”, Ekaterinburg, Russia, 2017, pp. 176-188 (in Russian).

21.Lokshina S.M. (1988) Short dictionary of foreign words. Moscow: Russian Language (in Russian).

22.Ozhegov S.I. (2010) Explanatory dictionary of the Russian language: About 100,000 words, terms and phraseological expressions. Moscow: Oniks (in Russian).

23.Brokgauz F.A., Efron I.A. (2004) Encyclopedic dictionary. Society and the state. Rulers and generals. Peoples and countries. Moscow: EKSMO (in Russian).

24.Lapin I.K., ed. (2006) Large encyclopedic dictionary: More than 100,000 articles, more than 4,000 illustrations. Moscow: ACT (in Russian).

25.Chebotarev V.G., Gromov A.I. (2014) Automating the learning process. Business Informatics, no 4, pp. 45-52 (in Russian).

26.Zharov V.K., Taratukhina Yu,V. (2014) Peculiarities of functioning of the information and educational environment of modern higher education. Business Informatics, no 2, pp. 44-50 (in Russian). 


\section{About the author}

\section{Rimma D. Gutgarts}

Dr. Sci. (Econ.), Professor;

Irkutsk National Research Technical University, Institute of Information Technology and Data Analysis, 83, Lermontov Street, Irkutsk 664074, Russia;

E-mail: gutgarc@gmail.com

ORCID 0000-0001-9881-1976 